Research paper

\title{
Flow cytometric methods for prenatal and neonatal diagnosis
}

\author{
Michèle G. Curtis ${ }^{\mathrm{a}}$, Brooke Walker ${ }^{\mathrm{b}}$, Thomas N. Denny ${ }^{\mathrm{b}, \mathrm{c}, *}$ \\ a Department of Obstetrics and Gynecology, University of Texas, Houston, TX 77026, United States \\ ${ }^{\mathrm{b}}$ Duke Human Vaccine Institute, Duke University Medical Center, Durham, NC 27710, United States \\ c Immunology Quality Assurance Center, Duke Human Vaccine Institute, Duke University Medical Center, Durham, NC 27710, United States
}

\section{A R T I C L E I N F O}

\section{Article history:}

Received 29 September 2010

Accepted 29 September 2010

Available online 13 October 2010

\section{Keywords:}

Flow cytometry

Fetal cell sorting

Prenatal diagnosis

Pediatric immunological disorders

Pediatric hematological disorders

\begin{abstract}
A B S T R A C T
Flow cytometry offers a promising alternative to the current methods of amniocentesis or chorionic villus sampling (CVS) for fetal cell sorting for prenatal diagnosis. While flow cytometric methods have been greatly improved to be more sensitive at detecting fetal cells within the maternal circulation, there are still several challenges that need to be overcome before application in prenatal diagnosis. However, flow cytometry is a powerful tool that can be used to enhance molecular testing and other diagnostic testing modalities in prenatal and neonatal diagnosis. It remains the gold standard to identify cellular immunodeficiencies and, for some immunological disorders with established biomarkers, flow cytometric assays can be used to make a definitive diagnosis. In this review, the advantages and disadvantages of using MACS and FACS analysis for fetal cell sorting are discussed. This review also includes an overview of the current flow cytometric assays and biomarkers that may be used for prenatal and neonatal diagnosis of common immunological and hematological abnormalities and the role of flow cytometry in treatment monitoring after bone marrow and stem cell transplantation.
\end{abstract}

(C) 2010 Elsevier B.V. All rights reserved.

\section{Introduction}

Flow cytometry has evolved from the bench into cutting edge technology that can be used in a variety of fields in clinical medicine. In the area of prenatal diagnosis, flow cytometry offers a promising though technologically challenging alternative to the current methods of amniocentesis or chorionic villus sampling (CVS) as the latter are invasive, carry a risk of fetal injury, may result in pregnancy loss, and expensive. During pregnancy, fetal cells are present in the maternal circulation, albeit in very small quantities ( 1 fetal cell in $1 \times 10^{4}$ to $1 \times 10^{7}$ nucleated maternal cells) (Bischoff et al., 1998). The ability to isolate and utilize these cells using noninvasive and inexpensive methods would greatly advance the field of prenatal diagnosis. High-throughput methodologies such as magnetic-activated cell sorting (MACS) and single

\footnotetext{
* Corresponding author. Duke Human Vaccine Institute, 2 Genome Court, MSRB II-Room 4077, DUMC Box 103020, Durham, NC 27710, United States. Tel.: +1 919681 1023; fax: +19196845230.

E-mail address: thomas.denny@duke.edu (T.N. Denny).
}

cell fluorescence-activated cell sorting (FACS) analysis can be used to isolate fetal nucleated erythrocytes in maternal blood for use in prenatal screening tests. These methods are relatively inexpensive compared to invasive techniques such as amniocentesis or CVS though the initial investment to acquire the equipment can be expensive. Flow sorting protocols have proved challenging however, with cell expression levels often being too low for clinical application. One particular challenge is that there are currently no fetal-specific cell markers (e.g. PBMC's) that can be targeted for identifying fetal cells in the maternal circulation.

Despite their current limitations, flow cytometric assays can be used to diagnose many immunological and hematological disorders and chromosomal abnormalities prenatally and in the neonatal state. Flow cytometric assays can be used for $\mathrm{T}$ cell, $\mathrm{T}$ subset enumeration, natural killer (NK) cell enumeration (CD3, CD4, CD8, CD16, CD56) and to assess T cell function including lymphocyte activation and proliferation responses to mitogens or antigens. $B$ cell enumeration can be performed using flow cytometry to assess the percentage of lymphocytes reacting with fluorescently-labeled antibodies 
to B cell-specific antigens. In conjunction with interphase cytogenetic or DNA analysis, protein-based flow cytometry can offer confirmatory diagnosis of the DNA analysis and can assist in genetic carrier identification. Flow cytometry is the gold standard to detect cellular immunodeficiencies in children and, for some immunological disorders with established biomarkers, flow cytometric assays are used to make the definitive diagnosis. Flow cytometry has applications for patient treatments as well; it is the gold standard for monitoring immune reconstitution following hematopoietic bone marrow or stem cell transplantation for the treatment of immunodeficiencies.

A challenge for the field is to define more sensitive biomarkers for diseases that can be used for population screening and prenatal diagnosis. For example, one common immune disorder is severe combined immune deficiency syndrome (SCID) characterized by a defect in $\mathrm{T}$ and $\mathrm{B}$ lymphocytes resulting in a patient's susceptibility to severe or life-threatening infections. Previous screening of SCID in newborns was based on counting T lymphocytes in umbilical cord blood; however, this method was not cost-effective and has been shown to produce a high rate of false-negatives and false-positives (Puck and SCID Newborn Screening Working Group, 2007). Patients diagnosed with SCID have severe $\mathrm{T}$ cell lymphopenia as indicated by a complete absence of T-cell receptor excision circles (TREC's). Using flow cytometric enrichment procedures, it is now possible to detect the presence of TREC's in blood drawn for newborn screening tests (Puck and SCID Newborn Screening Working Group, 2007). As more biomarkers are identified, the use of flow cytometry as a tool in clinical settings will be more widely applicable.

Given the promise and potential for flow cytometric methods to enhance and advance prenatal diagnosis of diseases, as well as its burgeoning role in diagnosis and treatment of various disease states, a comprehensive overview of this technology is in order. This review will include a discussion of the current flow cytometry methods for fetal cell sorting, as well as an overview of the current flow cytometric assays and biomarkers that may be used for prenatal and neonatal diagnosis of common immunological and hematological abnormalities. The role of flow cytometry in treatment monitoring after bone marrow and stem cell transplantation will also be discussed.

\section{Techniques for isolating fetal cells for use in specialized testing}

High throughput methodologies are required to successfully isolate fetal cells from the maternal cell population as their frequency is very low. Current methodologies for fetal cell sorting are magnetic-activated cell sorting analysis (MACS) and single cell fluorescence-activated cell sorting (FACS). MACS analysis uses magnetic beads conjugated to antibodies that to bind to cell surface antigens that can be separated either positively or negatively. The beads can also be coated with fluorescently labeled antibodies against the targeted antigen for cell separation and their purity easily determined using a flow cytometer. The advantages of MACS analysis are that it is fast, relatively inexpensive, and highly specialized personnel are not required to run the analysis (Hahn and Holzgreve, 2002). For fetal cell enrichment, MACS has been used to deplete maternal cells using monoclonal antibodies to CD45 alone or in combination with CD14 monoclonal antibodies. The CD45- or CD14- cells can then be labeled with a fetal cell marker to target fetal cells within the population. Using a triple density gradient with antiCD71-labeled cells, Gänshirt et al. (1998) showed that the frequency of fetal NRBCs increases with gestational age with yields ranging from 100 to 1000 cells per $40 \mathrm{~mL}$ of maternal blood from week 6 of gestation to term.

Herzenberg first used fluorescence-activated cell sorting (FACS) to successfully isolate fetal cells in maternal blood in 1979 (Herzenberg et al., 1979). Using maternal peripheral blood samples, fetal cells were stained by indirect immunofluorescence using a rabbit antiserum targeting paternal HLA cell surface antigens absent in the mother followed by a fluorescein-conjugated goat anti-rabbit immunoglobulin. Fetal cells were positively sorted based on the presence of HLA. Bianchi et al. (1990) demonstrated that fetal nucleated red blood cells (NRBC's) could be isolated from the maternal population using a FACS enrichment procedure targeting the transferring receptor (TfR) on the surface of NRBC's. After staining NRBC's with fluorescein-conjugated anti-TfR and phycoerythrin-conjugated anti-TfR, they were able to sort out NRBC's for PCR analysis. They were able to detect the Y chromosomal sequence in $75 \%$ of the male-bearing pregnancies demonstrating the feasibility of isolating fetal genetic material from maternal blood for potential prenatal diagnosis of fetal aneuploidies. Price et al. (1991) demonstrated that fetal cells could successfully be sorted from the maternal population based on staining for the transferring receptor and glycophorin-A cell surface molecule. Using PCR analysis on flow-sorted cells, they correctly identified fetal male fetuses in 12 of $12(100 \%)$ pregnancies and female fetuses in 5 of 6 (83\%) pregnancies in the study. Using in situ hybridization with chromosome-specific deoxyribonucleic acid probes, they were able to identify one case of trisomy 21 and one case of trisomy 18 in maternal blood.

A 2000 study compared MACS analysis to FACS analysis for the recovery of fetal NRBCs using an anti-gamma globin antibody (Wang et al., 2000). MACS analysis with CD45 depletion followed by staining for positive selection of fetal NRBCs had a higher specificity for NRBCs and less cell loss following FISH analysis as compared to FACS. In contrast, FACS analysis recovered a higher purity and higher yield of fetal NRBCs and had higher efficiency with FISH analysis than MACS. However, MACS offers a faster, more cost-effective method where FACS analysis requires expensive equipment and highly trained personnel to run the analysis.

The Fetal Cell Isolation Study (NIFTY) in 2002 was a 5 year prospective clinical evaluation of pregnant women at risk for fetal abnormalities carried out by the National Institute of Child Health and Human Development (Bianchi et al., 2002). The purpose of the study was to compare the success rates of detecting fetal gender and fetal aneuploidy using fluorescence in situ hybridization (FISH) analysis on interphase nuclei of fetal cells in the maternal circulation to metaphase karyotypes of fetal cells obtained from amniocentesis or chorionic villus sampling. Inclusion criteria for patients included being 35 years of age or older, having an abnormal fetal sonogram, or a history of fetal aneuploidies. Processing centers using MACS analysis targeted CD71+ cells while centers using Fluorescence-Activated Cell Sorting (FACS) 
targeted $\mathrm{HbF}+$ cells and once the cells were sorted, they were sent to laboratories for FISH analysis. Based on 2744 samples, the study found that MACS analysis was more sensitive than FACS in detecting fetal gender as the success rate using MACS was $48 \%$ compared to $13 \%$ using FACS ( $p=0.0001$ ). Overall, the detection rate for fetal gender was $41.4 \%$ and the detection rate for fetal aneuploidy was $74.4 \%$.

Despite the capability of flow cytometry to identify fetal cells in maternal blood, the application of this method for prenatal diagnosis still needs much work for its integration into routine clinical practice. While studies have demonstrated that FACS and MACS can successfully isolate fetal cells, the cell yield is often too low to make critical diagnoses of fetal abnormalities. A large scale clinical trial is needed that assesses flow cytometric techniques in combination with FISH analysis or genetic analysis to evaluate outcomes and the rate of false positives and false negatives. Currently, the most lacking area related to this application is in the development of fetal cell-specific markers.

\section{Cell markers of infection}

The diagnosis of late onset nosocomial infections in preterm very low birth weight (VLBW) infants is important as these infections are associated with high morbidity and mortality. Preterm VLBW infants present with an immature immune system and because of their need for care in critical care settings whereby arterial or venous catheters are in use, up to $25 \%$ of these infants may develop a nosocomial infection with $10 \%$ at risk of death from the infection ( $\mathrm{Ng}$ et al., 2002). A reliable marker of infection or a set of markers that can quickly and accurately diagnose these infections using small volumes of peripheral blood could lead to faster, more effective treatment. A variety of biomarkers have been studied that include hematologic parameters such as immature/total neutrophil ratio (Rodwell et al., 1988 and Berger et al., 1995), C-reactive protein (Berger et al., 1995; Ng et al., 1997; Wagle et al., 1994; and Hatherill et al., 1999), procalcitonin (Hatherill et al., 1999; Gendrel et al., 1996), TNF- $\alpha$ (Ng et al., 1997), IL-1ß (Ng et al., 1997), soluble IL-1ra (Küster et al., 1998), IL-2 receptor (Jurges and Henderson, 1996), IL-6 (Ng et al., 1997 and Küster et al., 1998), IL-8 (Franz et al., 1999 and Berner et al., 2000), IL-10 (van der Poll et al., 1997) and markers of complement activation (Zilow et al., 1993). Each of these markers offers some utility to the clinician during acute care of the infant, but they have yet to become a routine test for care of acutely ill infants in most settings. More recently, the flow cytometric measurement of CD64, CD11b (two neutrophil markers and CD25 and CD45RO (two lymphocyte markers) have been studied (Hoffmann, 2009 and $\mathrm{Ng}$ et al., 2002) with the neutrophilic expression of CD64 being superior for detecting systemic sepsis compared to the other markers noted above. CD64 expression (up-regulated) has been shown to offer high sensitivity ( $90 \%$ or more) with high specificity (90-100\%) in both adults and children for detection of sepsis (Hoffmann, 2009).

\subsection{Flow cytometric assays for diagnosis}

Small volumes (e.g. $0.05 \mathrm{~mL}$ ) of peripheral blood collected in EDTA (e.g. heel stick or venous sample) are obtained and neutrophils are labeled with a directly conjugated anti-CD64 monoclonal antibody using a standard lyse no wash process. The flow cytometer should be set up using a calibrated fluorescence intensity bead system prior to measuring CD64 expression on patient cells. Fresh cells from a healthy donor should be run in parallel to the patient sample and used to compare the amount of up-regulation of CD64 expression as illustrated in Fig. 1.

\section{Immune deficiencies}

Primary immunodeficiency diseases result from genetic defects and while more than 130 different types have been identified, they are rare. Approximately 50,000 new cases are identified each year in the United States. Congenital immunodeficiencies may occur as a result of defects in B lymphocytes, T lymphocytes, or both and they typically result in a patient's increased susceptibility to recurrent or severe infections (Notarangelo, 2010). They are most commonly diagnosed within the first 2 years of life when symptoms first start to appear and without therapeutic intervention, they are typically fatal. Newborn diagnosis would allow for earlier treatment with prophylaxis against opportunistic infections and curative treatment with bone marrow or hematopoietic stem cell transplantation. Prenatal diagnosis is the ultimate goal, however, because it would then allow for in utero treatment resulting in a normal healthy birth.

\subsection{Severe combined immunodeficiency (SCID)}

Severe combined immunodeficiency disorder (SCID) is characterized by a virtual lack of functional peripheral T cells although both cellular and humoral immune responses are impaired in affected individuals. It is usually diagnosed in the first year of life and infants will commonly present with a fungal infection of the mouth (thrush), diarrhea, failure to thrive, and serious bacterial or viral infections. Infants with SCID have severe $\mathrm{T}$ cell lymphopenia with less than $20 \% \mathrm{~T}$ cells compared to a normal percentage range of 55\% to $75 \%$

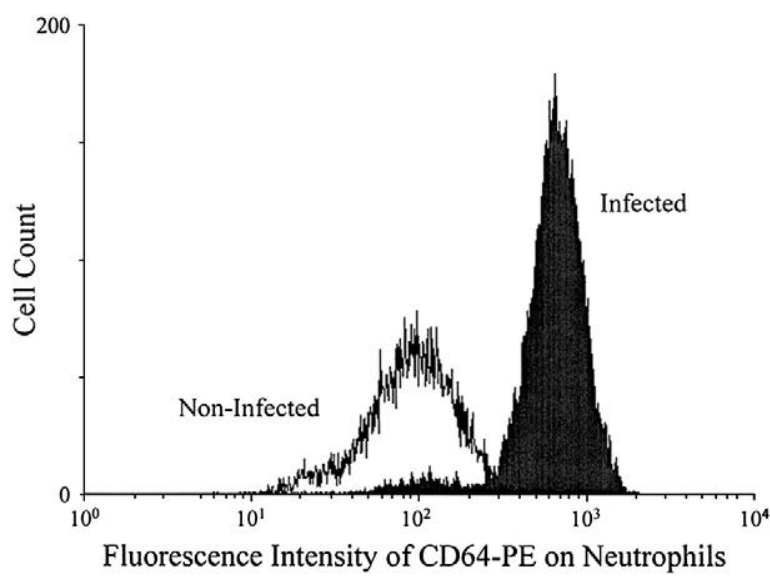

Fig. 1. Flow cytometric analysis of CD64 expression on neutrophils in a typical infected infant and in a noninfected infant.

Source: Ng, P.C., Li, K., Wong, R.P.O., Chui, K.M., Wong, E., Fok, T.F., 2002. Neutrophil CD64 expression: a sensitive diagnostic marker for late-onset nosocomial infection in very low birthweight infants. Pediatr. Res. 51, 296-303. 
(Kobrynski, 2006). Forms of SCID are classified according to immunological phenotype, (1) $\mathrm{T}^{-} \mathrm{B}^{+}$SCID is characterized by the absence of $\mathrm{T}$ lymphocytes, but presence of $\mathrm{B}$ lymphocytes and (2) $\mathrm{T}^{-} \mathrm{B}^{-}$SCID is characterized by the absence of both $\mathrm{T}$ and B lymphocytes. The most common form of SCID is linked to the $\mathrm{X}$ chromosome and affects only males (SCIDX1) (Notarangelo, 2010). Patients with SCIDX1 lack both T and NK cells. SCIDX1 is caused by mutations of the IL-2 receptor gamma gene (IL2RG) on the X chromosome, which encodes for the common gamma chain $(\gamma \mathrm{c})$ shared by cytokine receptors for IL-2, IL-4, IL-7, IL-9, IL-15, and IL-21. SCIDX1 has a prevalence of $1: 20,000$ births and accounts for $46 \%$ of all SCID cases (Boyle and Buckley, 2007). Other forms of SCID usually follow an autosomal recessive inheritance pattern or are the result of spontaneous mutations. One of these other forms is linked to a deficiency of the enzyme adenosine deaminase (ADA). ADA is required by all body cells to produce new DNA and to breakdown metabolites that are toxic to lymphocytes. It is estimated that 40-100 infants are diagnosed with SCID each year, although the actual prevalence may be higher due to undiagnosed cases. It is not routine to do specific white blood cell counts in newborns, so the diagnosis is often made after the infant has presented with severe or recurrent infections and failure to thrive. The average age of diagnosis with SCID is about 6 months.

\subsubsection{Flow cytometric assays for diagnosis}

Diagnosis of SCID can be performed using flow cytometry by measuring $\mathrm{T}$ cell enumeration and $\mathrm{T}$ cell proliferation after stimulation with antigens or mitogens (CD69, CD25, CD71, CD45RO, CD45RA, CD40 ligand). T cell measurements can then be compared to age-matched controls (Table 1). A negative (e.g. absent) response to mitogens is typical of SCID. TREC's are exported to the peripheral circulation by newly generated $\mathrm{T}$ lymphocytes produced in the thymus and are high in newborns and infants. There are no TRECs in infants with SCID (Notarangelo, 2010). In January 2010, SCID was recommended to be added to the mandatory newborn screening panel by the U.S. Department of Health and Human Services Secretary's Advisory Committee for Heritable Disorders in Newborns and Children (ACHDNC). The decision is currently under review by the Secretary of Health and Human Services. It is believed that

Table 1

Normal human blood lymphocyte subpopulations at various ages, Immunologic Disorders in Infants and Children 4th edition, 1996.

Source: Stiehm, E. R., 1996. Immunologic Disorders in Infants and Children, fourth ed. W.B. Saunders Company, Philadelphia.

\begin{tabular}{|c|c|c|c|c|c|c|c|}
\hline \multicolumn{8}{|l|}{ Age groups } \\
\hline $\begin{array}{l}\text { Subpopulations } \\
\text { (cells/ } \mu \mathrm{I} \text { ) }\end{array}$ & Cord blood & $2-3$ months & 4-8 months & 12-23 months & $2-5$ years & 7-17 years & Adult \\
\hline \multicolumn{8}{|l|}{ Total lymphocytes } \\
\hline Median (\%) & $5400(41 \%)$ & $5680(66 \%)$ & $5990(64 \%)$ & $5160(59 \%)$ & $4060(50 \%)$ & $2400(40 \%)$ & $2100(32 \%)$ \\
\hline $\begin{array}{l}\text { Confidence } \\
\text { intervals (\%) }\end{array}$ & $\begin{array}{l}4200(35 \%) \\
\text { to } 6900(47 \%)^{*}\end{array}$ & $\begin{array}{l}2920(55 \%) \\
\text { to } 8840(78 \%)\end{array}$ & $\begin{array}{l}3610(45 \%) \\
\text { to } 8840(79 \%)\end{array}$ & $\begin{array}{l}2180(44 \%) \\
\text { to } 8270(72 \%)\end{array}$ & $\begin{array}{l}2400(38 \%) \\
\text { to } 5810(64 \%)\end{array}$ & $\begin{array}{l}2000(36 \%) \\
\text { to } 2700(43 \%)^{*}\end{array}$ & $\begin{array}{l}1600(28 \%) \\
\text { to } 2400(39 \%)^{*}\end{array}$ \\
\hline \multicolumn{8}{|l|}{ CD3 T cells } \\
\hline Median (\%) & $3100(55 \%)$ & $4030(72 \%)$ & $4270(71 \%)$ & $3300(66 \%)$ & $3040(72 \%)$ & $1800(70 \%)$ & $1600(73 \%)$ \\
\hline $\begin{array}{l}\text { Confidence } \\
\text { intervals (\%) }\end{array}$ & $\begin{array}{l}2400(49 \%) \\
\text { to } 3700(62 \%)^{*}\end{array}$ & $\begin{array}{l}2070(55 \%) \\
\text { to } 6540(78 \%)\end{array}$ & $\begin{array}{l}2280(45 \%) \\
\text { to } 6450(79 \%)\end{array}$ & $\begin{array}{l}1460(53 \%) \\
\text { to } 5440(81 \%)\end{array}$ & $\begin{array}{l}1610(62 \%) \\
\text { to } 4230(80 \%)\end{array}$ & $\begin{array}{l}1400(66 \%) \\
\text { to } 2000(76 \%)^{*}\end{array}$ & $\begin{array}{l}960(61 \%) \\
\text { to } 2600(84 \%)^{*}\end{array}$ \\
\hline \multicolumn{8}{|l|}{ CD4 T cells } \\
\hline Median (\%) & $1900(35 \%)$ & $2830(52 \%)$ & $2950(49 \%)$ & $2070(43 \%)$ & $1800(42 \%)$ & $800(37 \%)$ & $940(46 \%)$ \\
\hline $\begin{array}{l}\text { Confidence } \\
\text { intervals (\%) }\end{array}$ & $\begin{array}{l}1500(28 \%) \\
\text { to } 2400(42 \%)^{*}\end{array}$ & $\begin{array}{l}1460(41 \%) \\
\text { to } 5116(64 \%)\end{array}$ & $\begin{array}{l}1690(36 \%) \\
\text { to } 4600(61 \%)\end{array}$ & $\begin{array}{l}1020(31 \%) \\
\text { to } 3600(54 \%)\end{array}$ & $\begin{array}{l}900(35 \%) \\
\text { to } 2860(51 \%)\end{array}$ & $\begin{array}{l}700(33 \%) \\
\text { to } 1100(41 \%)^{*}\end{array}$ & $\begin{array}{l}540(32 \%) \\
\text { to } 1660(60 \%)^{*}\end{array}$ \\
\hline \multicolumn{8}{|l|}{ CD8 T cells } \\
\hline Median (\%) & $1500(29 \%)$ & $1410(25 \%)$ & $1450(24 \%)$ & $1320(25 \%)$ & 1180 & $800(30 \%)$ & $520(27 \%)$ \\
\hline $\begin{array}{l}\text { Confidence } \\
\text { intervals (\%) }\end{array}$ & $\begin{array}{l}1200(26 \%) \\
\text { to } 2000(33 \%)^{*}\end{array}$ & $\begin{array}{l}650(16 \%) \\
\text { to } 2450(35 \%)\end{array}$ & $\begin{array}{l}720(16 \%) \\
\text { to } 2490(34 \%)\end{array}$ & $\begin{array}{l}570(16 \%) \\
\text { to } 2230(38 \%)\end{array}$ & $\begin{array}{l}630(22 \%) \\
\text { to } 1910(38 \%)\end{array}$ & $\begin{array}{l}600(27 \%) \\
\text { to } 900(35 \%)^{*}\end{array}$ & $\begin{array}{l}270(13 \%) \\
\text { to } 930(40 \%)^{*}\end{array}$ \\
\hline \multicolumn{8}{|c|}{$B$ cells (CD19 or CD20) $\dagger$} \\
\hline Median (\%) & $1000(20 \%) \dagger$ & $900(23 \%)$ & $900(23 \%)$ & $900(23 \%)$ & $900(24 \%)$ & $400(16 \%) \dagger$ & $246(13 \%) \dagger$ \\
\hline $\begin{array}{l}\text { Confidence } \\
\text { intervals (\%) }\end{array}$ & $\begin{array}{l}200(14 \%) \\
\text { to } 1500(23 \%)^{*}\end{array}$ & $\begin{array}{l}500(19 \%) \\
\text { to } 1500(31 \%)\end{array}$ & $\begin{array}{l}500(19 \%) \\
\text { to } 1500(31 \%)\end{array}$ & $\begin{array}{l}500(19 \%) \\
\text { to } 1500(31 \%)\end{array}$ & $\begin{array}{l}700(21 \%) \\
\text { to } 1300(28 \%)\end{array}$ & $\begin{array}{l}300(12 \%) \\
\text { to } 500(22 \%)^{*}\end{array}$ & $\begin{array}{l}122(10 \%) \\
\text { to } 632(31 \%)\end{array}$ \\
\hline \multicolumn{8}{|l|}{ CD4:CD8 ratio } \\
\hline Median & 1.2 & 2.2 & 2.1 & 1.6 & 1.4 & 1.3 & 1.7 \\
\hline $\begin{array}{c}\text { Confidence } \\
\text { intervals }\end{array}$ & 0.8 to 1.8 & 1.3 to 3.5 & 1.2 to 3.5 & 1.0 to 3.0 & 1.0 to 2.1 & 1.1 to 1.4 & 0.9 to 4.5 \\
\hline
\end{tabular}

Confidence intervals given are the 5 th to 95 th percentiles except where indicated $\left(^{*}\right)$; these are the 25 th to 75 th percentiles. B cells use the CD20 antigen except where indicated $(\dagger)$; these use the CD19 antigen. The lymphocyte \% is the percentage of total leukocytes. The CD3, CD4, CD8, and B cell (CD19 or CD20) \% is the percentage of total lymphocytes.

Combined data from Erkellor-Yuksel FM. et al. J Pediatr. 120:216-222, 1992 (cord blood, 7-17 years; B cells); Denny T. et al. JAMA 267:1484-1488, 1992 (2-3 mo to 5 years); Fahey JL, cited in Giorgi JV et al. In Rose NR, et al. Manual of Clinical Laboratory Immunology, 4th ed. Washington, D.C., American Society for Microbiology, 1992, pp. 174-181 (adults).

Each subgroup contains at least 22 normal subjects. 
the inclusion of SCID into the newborn screening panel should result in higher survival rates because an earlier diagnosis allows for greater chance of successful treatment by bone marrow or stem cell transplantation, thus precluding the need to put the patient on lifelong IV drug therapy. In addition, early diagnosis would protect these immunocompromised infants from potentially severe disease or reactions induced by vaccine strain viruses present in recommended newborn and infant immunization schedules (Puck and SCID Newborn Screening Working Group, 2007).

\subsubsection{Flow cytometric assays for treatment monitoring}

The most successful treatment method for SCID is bone marrow transplantation (BMT) or hematopoietic stem cell transplantation (HSCT). Transplantation can be performed within the first 3 months of life and offers a 95\% survival rate (Buckley et al., 1999). Children with untreated SCID rarely live past the age of two. The earlier the diagnosis of SCID, including prenatally, the better, as immune reconstitution must be monitored closely following transplantation because delayed or incomplete reconstitution can put patients at risk for lethal infections and complications from autoimmunity (Puck and SCID Newborn Screening Working Group, 2007). Flow cytometric assays performing $\mathrm{T}$ and $\mathrm{B}$ cell subset enumeration offer a powerful tool to assess immune reconstitution immediately following transplantation and for long term follow-up post-surgery to ensure that lymphocyte counts reach and remain at normal levels.

In HLA haploidentical T cell-depleted BMT, full immune reconstitution is not achieved until several years after the procedure; therefore, a goal for transplantation therapy is to achieve immune reconstitution as early as possible. In a small number of cases, in utero BMT and HSCT have been successful in treating SCID (Bartolomé et al., 2002; Westgren et al., 2002). Bartolomé et al. (2002) demonstrated a successful case of in utero CD34+ cell transplantation in a T-B + NK + SCID affected fetus. In this case, BM CD34+ cells were transplanted in utero and lymphocyte immunophenotyping confirmed lymphoid engraftment and restoration of $\mathrm{T}$ cell function early on after BMT. Conjugated mAb anti-CD3 (FITC)/Cd19 (PE/)CD45 were used to evaluate $B$ lymphocytes after 3 years post-fetal surgery and revealed that absolute $B$ cell numbers remained within normal age-matched levels. Westgren et al. (2002) demonstrated that transplantation of cryopreserved fetal liver cells at 14 weeks in utero results in engraftment at 24 weeks of gestation as indicated by phenotypic analysis with flow cytometry that showed that all T lymphocytes and NK cells were of donor origin, but that B lymphocytes (CD19+) were of host origin. $T$ cell enumeration indicated that the total lymphocyte count and the number of CD3 $+\mathrm{T}$ lymphocytes were normal at birth (Westgren et al., 2002). Additionally, it has recently been demonstrated in mice that transplantation with enriched stem and progenitor cells to treat SCIDX1 results in faster B cell and $\mathrm{T}$ cell reconstitution as confirmed by FACS analysis when performed in utero than during neonatal (postnatal days 1-4) or adolescent (4-6 weeks old) HSCT (Liuba et al., 2009). These studies proved that restoration of a fully functional immune system can be achieved after treatment for SCID with in utero BMT and in utero HCST and these approaches offer faster immune reconstitution compared to $\mathrm{T}$ cell-depleted, haploidentical post-natal BMT and HCST.

\subsection{DiGeorge syndrome}

DiGeorge syndrome, also referred to as velocardiofacial syndrome, but now more commonly called 21q11 deletion syndrome, is a group of disorders characterized by a variety of medical problems that vary from patient to patient. Because the signs and symptoms of 22q11.2 deletion syndrome are so varied, different groupings of features were once described as separate conditions. Patients with DiGeorge syndrome may present with palatal defects, cardiac defects, hypoparathyroidism (and resulting hypocalcemia), a thymic defect (hypoplasia or aplasia), renal problems, and facial dysmorphisms. Diagnosis is usually made soon after birth. There is great variation in the symptoms associated with DiGeorge Syndrome, even among affected members in the same family; treatment is based on the symptoms that are present. A hemizygous deletion of chromosome $22 q 11$ has been observed in $35 \%$ to $90 \%$ of patients and a minority of patients show a deletion of 10p13-14 (Notarangelo, 2010). The majority of patients with impaired thymic development typically present with mild to moderate $\mathrm{T}$ cell deficiency while the minority $(<1 \%)$ present with a complete absence of $\mathrm{T}$ cells known as complete DiGeorge syndrome. The prevalence of DiGeorge syndrome is approximately 1 per 3000-5000 live births (Kobrynski, 2006). The condition may be more prevalent than these estimates, however, as some affected individuals have few signs or symptoms and are never diagnosed.

\subsubsection{Flow cytometric assays for diagnosis}

Diagnosis of DiGeorge syndrome can be determined using flow cytometry to assess T-cell lymphopenia. A limited confirmatory flow cytometry screening test was recently developed to aid in the diagnosis of severe $\mathrm{T}$ cell lymphopenia (Routes et al., 2009). The test enumerated the total number of CD3 T cells, CD3 CD4 T cells, CD3 CD8 T cells, CD3 CD4 CD45RO memory CD4 T cells, CD3 CD8 CD45RO memory CD8 T cells, CD3 CD56 natural killer cells, and CD19 B cells. One to two milliliters of whole blood collected in sodium heparin tubes was stained with antibodies to CD3-FITC (SK7), CD4-PE (SK3), CD8-PE (SK1), CD19-PE (SJ25C1), CD45-PE (2D1), CD56-APC, and CD45ROPerCP and analyzed on a flow cytometer. The test successfully screened 11 of 37 (30\%) infants with abnormal TREC assays for T cell lymphopenia and found that 3 of 11 infants had normal T cell counts while 8 of 11 (73\%) infants had T-cell lymphopenia. Two of 8 infants (25\%) with T-cell lymphopenia were subsequently diagnosed as having DiGeorge syndrome based on persistent T-cell lymphopenia; in one case the presence of phenotypically unusual lymphocytes that decreased over time and in the other case there were decreased B cells, CD4, and CD8 $\mathrm{T}$ cells with increased numbers of activated or memory $\mathrm{T}$ cells. Although a finding of very low to absent $\mathrm{T}$ cells in peripheral blood suggests severe immunodeficiency, decisions regarding treatment should be based on T-cell proliferative responses to antigens, not on the number of T cells. The TREC and flow assays can be followed by fluorescent in situ hybridization (FISH) for the 22q11 region for a definitive diagnosis. Prenatal diagnosis can be accomplished by FISH and molecular analysis on amniotic fluid or chorionic villous sampling.

\subsubsection{Flow cytometric assays for treatment monitoring}

Thymus transplantation is the recommended treatment for patients with a complete absence of $\mathrm{T}$ cells, or complete 
DiGeorge syndrome (Markert et al., 2003). Early thymus transplantation before the onset of infectious complications may promote successful immune reconstitution. T-cell function may improve in patients with partial DiGeorge anomaly; therefore, thymus transplantation is not indicated for these patients. Flow cytometry can be used in conjunction with intracellular cytokine analysis to evaluate phenotypical and functional properties of T cells following engraftment. There are several markers of $\mathrm{T}$ cell reconstitution that can be assessed using multicolor flow cytometric analysis. The CD45RA+/CD45RO-, CD45RA+/CD62L+, and CD45RO-/ CD27+/CD95 (low) phenotypes can be used as markers for naïve T cells and CD103 and CD11a can be used as markers of naïve CD8 + T cells (Hudson et al., 2007). The most commonly used phenotype for freshly isolated whole blood is CD45RA+/ CD45RO-/CD62L + and the CD45RO+/CCR7-/ CD62L+/phenotype is frequently used to identify effector memory $\mathrm{T}$ cells, and CD45RO+/CCR7+/ CD62L + is frequently used to identify central memory $\mathrm{T}$ cells.

\subsection{Chronic granulomatous disease}

Chronic granulomatous disease (CGD) is a genetic disorder of the innate limb immune system characterized by failure of phagocytes to produce microbicidal reactive oxygen species (ROS) which results in severe susceptibility to bacterial and fungal infections (Koker et al., 2006). This phagocytic defect is caused by mutations in the four genes encoding the NADPH oxidase (nicotinamide adenine dinucleotide phosphate-oxidase) components including gp91phox, p22-phox, p47-phox or p67-phox. Patients presenting with CGD often have skin abscesses, liver abscesses, osteomyelitis, aspergillus, gastrointestinal or genitourinary obstruction, and chronic swelling of the lymph nodes. Patients with CGD have normal $\mathrm{T}$ and $\mathrm{B}$ cell function and do not have heightened susceptibility to viral infections. The most common molecular defect in chronic granulomatous disease is a mutation in the $C Y B B$ (cytochrome $B$, b subunit) gene that is located on the X chromosome and that encodes for gp91 (the b subunit of cytochrome b558). The resulting syndrome is commonly called X-linked chronic granulomatous disease (X-CGD). Gp91 deficiency accounts for $50-70 \%$ of all cases of chronic granulomatous disease. There are data to suggest that morbidity and mortality rates are highest in patients with the $\mathrm{X}$-linked form of the disease. The second most common mutation occurs in the NCF1 gene on chromosome 7 that encodes for $\mathrm{p} 47$. This mutation is the most common autosomal recessive form of the disease, and accounts for $20-40 \%$ of all cases. The condition is commonly diagnosed in childhood although in milder cases, the diagnosis may be delayed until adolescence or adulthood. The incidence of CGD is estimated to be $1: 200,000$ in the United States. Antimicrobial prophylaxis, early and aggressive treatment of infections, and interferon-gamma are the cornerstones of current therapy for CGD and the use of HSCT is controversial even when stem cells from a matched sibling donor are available. The current median survival duration for a patient with chronic granulomatous disease is estimated to be about 2025 years, with a mortality rate of $2-3 \%$ per year. The highest mortality rate is in children and the most common cause of death is infection.

\subsubsection{Flow cytometric assays for diagnosis}

The absolute neutrophil count (ANC) is markedly reduced in CGD (Notarangelo, 2010). Diagnosis of CGD can be made based on the evaluation of dihydrohodamine-123 (DHR-123) oxidation by flow cytometry. The DHR flow assay is rapid, objective and can detect the conversion of dihydrorhodamine (DHR)-1,2,3 to rhodamine-1,2,3. This assay is based on the respiratory burst of neutrophils in which the NADPH oxidase produces superoxide which stimulates neutrophils to generate hydrogen peroxide $\left(\mathrm{H}_{2} \mathrm{O}_{2}\right)$ (Richardson et al., 1998). The $\mathrm{H}_{2} \mathrm{O}_{2}$ oxidizes dihydrorhodamine (DHR)-1,2,3 and forms a strongly fluorescent rhodamine-1,2,3 (Koker et al., 2006). The DHR flow assay is also used to identify carriers with hyperlyonization (i.e. unequal representation of phagocytes expressing the normal and mutated gp91 genes); in these cases, individuals have two populations of neutrophils only one of which is capable of mediating DHR-123 oxidation.

\subsection{Wiskott-Aldrich syndrome}

Wiskott-Aldrich Syndrome (WAS) is an X-linked immunodeficiency disease with variable expression occurring almost exclusively in males and results from a defect of the WAS protein (WASp). The gene for WASp resides on

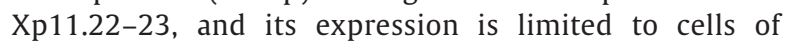
hematopoietic lineage. The prevalence of WAS is estimated to be 1-10 per 1 million males (Ochs and Thrasher, 2006). WAS causes persistent thrombocytopenia and, in its complete form, also causes small platelets, atopy, cellular and humoral immunodeficiency, and an increased risk of autoimmune disease and hematologic malignancy (Conley et al., 1999). The classic presentation of thrombocytopenia and bleeding, eczema, immunodeficiency and infection occurs in about 30\% of cases (Sullivan et al., 1994). In the newborn period, it may also present as bloody diarrhea. The WAS protein is involved in relaying signals from the cell surface to the actin cytoskeleton, a network of fibers that comprise a cell's structural framework. The actin cytoskeleton is important in determining cell shape and in allowing cells to move. Immune cells that lack WASP function do not respond normally to factors that trigger cell growth and division, have problems with cell movement, and difficulty attaching to other cells. While $\mathrm{T}$ and $\mathrm{B}$ cell lymphocyte counts may be normal or slightly reduced at infancy, T cell function declines over time, making WAS a progressive disorder. At this time, bone marrow transplant or cord blood stem cell transplant is the only cure. Without BMT, most males will die in their early $20 \mathrm{~s}$ due to infection or malignancy. Survival rates with bone marrow transplantation are 70-80\% (Ochs and Thrasher, 2006). When bone marrow transplant donor cannot be located, umbilical cord blood stem cell transplants have been used (Knutsen et al., 2003).

\subsubsection{Flow cytometric assays for diagnosis}

Protein-specific flow cytometric assays and functional assays can be used in the diagnosis of WAS and provide quantitative and morphologic information about cellular elements of the immune system as well as information about platelet numbers and morphology. Trifari et al. (2010) recently expressed the WAS protein (WASP) in cultured T cells by staining WASP on whole blood after fixation/ 
permeabilization by incubation with anti-WASP 5 A5 mAbs conjugated to AlexaFluor-488. Surface staining was performed using anti-CD3-APC, anti-CD19-APC, anti-CD27-phycoerythrin, anti-CD16-phycoerythrin, anti-CD56-APC, and anti-CD14-phycoerythrin mAbs. Unconjugated anti-WASP $5 A 5 \mathrm{mAbs}$ followed by anti-IgG $\mathrm{Ia}_{2 \mathrm{a}}$-phycoerythrin mAbs were also used. FACS analysis revealed expression of WASP in approximately $50 \%$ of the patient's $\mathrm{CD}^{+}{ }^{+}$and $\mathrm{CD}^{+}{ }^{+} \mathrm{T}$ cells (Trifari et al., 2010).

\subsection{Immune dysfunction polyendocrinopathy enteropathy $X$-linked syndrome (IPEX)}

Immunodysregulation polyendocrinopathy enteropathy, $\mathrm{X}$-linked syndrome (IPEX) is caused by mutations in the transcriptional activator FOXP3 gene, located on the $\mathrm{X}$ chromosome. The FOXP3 gene governs CD25 + CD4+ regulatory T cell (Treg) development and mutations in this gene cause the absence or dysfunction of regulatory T cells, and the subsequent development of severe autoimmunity and immune deficiency (Le and Geha, 2006). To date, 20 mutations in the FOXP3 gene have been identified in patients with IPEX syndrome (Ziegler, 2006). Patients typically present in infancy with enteropathy, dermatitis, failure to thrive and multiple endocrinopathies. Severe autoimmunity is common and type A1 diabetes mellitus may be manifest as early as 2 days of life. Children affected with IPEX syndrome usually die in the first 2 years of life due to failure to thrive, nutrient malabsorption, or infections secondary to immunosuppressive therapy. Bone marrow transplantation should be considered early in the disease to restore regulatory T-cell function, limit the autoimmune destruction of endocrine organs and possibly reduce the infectious complications from chronic immune suppression.

\subsubsection{Flow cytometric assays for diagnosis}

The lymphocyte phenotype of IPEX has been demonstrated using flow cytometry by Bakke et al. (2004) who found that the ratios of both $\mathrm{T}$ to $\mathrm{B}$ cells and CD4+ to CD8+ cells are elevated at birth, but CD4+ cells are not activated. They found that increases in HLA-DR + and CD25+ activated Tcells was associated with colitis and the onset of type I diabetes mellitus indicating that measures of activation, particularly HLA-DR + and CD25 + frequency, correlate well with the development of early active disease and may presage clinical episodes (Bakke et al., 2004). FOXP3-based flow cytometry can be used for diagnosis. Gavin et al. (2006) used a flow cytometric assay to express the FOXP3 protein from samples taken from IPEX patients. After staining with Foxp3specific rabbit polyclonal IgG and digoxigenin-labeled Foxp3specific mouse mAb (3 G3-dig), FOXP3 was detected with Alexa Fluor 488-conjugated 259D. They found that most IPEX patients studied lacked FOXP3-expressing cells confirming the association between a FOXP3 deficiency and the IPEX syndrome.

\subsection{X-linked hyper-IgM syndrome (X-HIM)}

There are two forms of hyper-IgM syndrome (HIM), X-linked hyper-IgM syndrome (X-HIM) and autosomal recessive hyperIgM syndrome (ARHIM). X-HIM is the more common of the two and affects only males. In both forms, levels of IgG and IgA are markedly reduced, but there are normal or increased levels of IgM. With X-HIM, levels of IgE are also absent or markedly reduced. In X-HIM syndrome, a gene mutation on chromosome Xq26.3.-27 prohibits normal expression of the CD40 ligand by activated CD4+ T lymphocytes, which need to interact with B lymphocytes bearing the CDO receptor to initiate the signal pathway for immunoglobulin isotope-switching (Freyer et al., 2004). Failure of the CD40 ligand on T cells to bind with CD40 on antigen-presenting cells is the cause of the immune deficiency in $\mathrm{X}$-HIM. While the clinical manifestations of X-HIM vary, most patients present with recurrent sino-pulmonary infections in the first 2 years of life. Patients with X-HIM are at an increased risk of opportunistic infections and as many as $20-40 \%$ of patients may present with Pneumocystis carinii pneumonia (Levy et al., 1997). Recurrent oral ulcers and proctitis are common and are usually associated with neutropenia, autoimmune disorders and lymphomas at an early age. X-HIM is associated with a high rate of liver diseases, the most common being sclerosing cholangitis and resulting from repeated infections with Cryptosporidium parvum, and patients also have an increased risk of gastrointestinal malignancy. Therapy with intravenous immunoglobulin may reduce the severity and frequency of infections but it does not reduce the risk of sclerosing cholangitis or malignancies. Even with intravenous immunoglobulins, the long-term survival rate in XHIM is poor. Actuarial survival curves show that less than $30 \%$ of the patients are alive at 25 years of age (Levy et al., 1997). The only cure for $\mathrm{X}-\mathrm{HIM}$ is bone marrow transplantation (BMT).

\subsubsection{Flow cytometric assays for diagnosis}

A flow cytometric assay is available for the diagnosis of $\mathrm{X}$ HIM syndrome. This assay is based on measuring the upregulation of the CD40 ligand (CD154 antigen) on activated CD4+ T lymphocytes. Freyer et al. (2004) have demonstrated a three color whole blood method requiring only a 4 hour in vitro stimulation of peripheral blood lymphocytes with PMA and ionomycin followed by incubation with an anti-154 monoclonal antibody and flow cytometric analysis. However, this assay may be complicated by several factors that may compromise T-cell activation including the use of immunosuppressive drugs, the presence of other undiagnosed underlying disorders, and the patient's age as CD40 ligand expression is difficult to detect in newborns and young infants (Notarangelo, 2010).

\subsection{X-linked agammaglobulinemia (XLA)}

$\mathrm{X}$-linked agammaglobulinemia (XLA) is a primary immunodeficiency disorder that results from Bruton's tyrosine kinase (BTK) gene mutation. The BTK gene is essential for normal B cell maturation and its mutation results in a defect of B-lymphocyte differentiation and markedly decreased levels of all major classes of immunoglobulins (IgG, IgA, IgE, IgM) and lack of specific antibody production. Patients with XLA present with recurrent bacterial infections, often at or near the surfaces of mucus membranes, such as the middle ear, sinuses, or lungs. Many of these infections may invade the bloodstream and spread to other internal organs as well. Because most of the bulk of tonsils and lymph nodes is made up of Blymphocytes, these tissues are absent or reduced in size on 
clinical exam in patients with XLA. The prevalence of XLA is 1 in 100,000 male newborns and is the most common form (85\%) of early onset agammaglobulinemia (Notarangelo, 2010). Most XLA patients who receive immunoglobulin on a regular basis lead relatively normal lives. Some patients benefit from the use of oral antibiotics every day to protect them from infection or to treat chronic sinusitis or chronic bronchitis.

\subsubsection{Flow cytometric assays for diagnosis}

A flow cytometric assay that uses anti-BTK mAbs can be used to detect a deficiency in BTK expression. Using intracellular staining of BTK on monocytes, Kanegane et al. (2001) demonstrated a 98\% detection rate of BTK deficiency. In this method, PBMC's were separated by Ficoll-Hypaque gradient centrifugation, stained with phycoerythrin-labeled anti-CD14 and anti-BTK mAbs followed by an IgG1 control and additional incubation with FITC-conjugated goat antimouse IgG1 antibody for FACS analysis (Kanegane et al., 2001). This assay should be used in conjunction with DNA sequencing for a definitive diagnosis.

4.8. X-ray sensitivity, cancer susceptibility, immunodeficiency, neurological abnormalities, and DNA double strand break repair dysfunction (XCIND) syndrome

XCIND syndrome is an autosomal recessive genetic disorder resulting in an inability to repair double strand breaks in the nucleus (Gatti et al., 2007). These defects affect V (D)J recombination, immunoglobulin class switching, and lymphocyte maturation and thus increase the risk of infections and cancer (Nahas and Gatti, 2009). The primary immunodeficiency disorders that fall into this syndrome all have nuclear defects that manifest as DNA double-stranded break (DSB) repair disorders and enhanced radiosensitivity, e.g., ataxia telangectasia (AT). Using AT as the prototype, other immunodeficiency disorders associated with DNA double strand break repair disorders include X-linked agammaglobulinemia (XLA), common variable immunodeficiency (CVID), and several variants of severe combined immunodeficiency (SCID). In contrast to this, other primary immunodeficiency disorders do not have associated DNA repair defects, e.g., HIM and do not exhibit radiosensitivity. Three new XCIND-like disorders have been described: RNF168 deficiency, RAD50 deficiency, and DNA-PKcs deficiency (Nahas and Gatti, 2009). The XCIND syndrome broadly encompasses chromosomal instability syndromes, DNA DSB repair disorders, and primary immunodeficiencies (Gatti et al., 2007).

\subsubsection{Flow cytometric assays for diagnosis}

There are several flow cytometric assays that can be used to detect DNA repair defects. After DNA damage forms double stranded breaks (DSB's), gamma-H2AX is formed with the phosphorylation of the histone, $\mathrm{H} 2 \mathrm{AX}$, and accumulates at the foci of DSB's to recruit DNA repair proteins (Nahas and Gatti, 2009). Antibodies conjugated with gamma-H2AX have been successfully used in flow cytometry to indicate DNA damage for diagnosis of ataxia telangiectasia (A-T) (Porcedda et al., 2008). A limitation of this method is that several kinases redundantly phosphorylate gammaH2AX, which can confound results (Nahas and Gatti, 2009). A functional flow cytometry (FFC) assay has been developed to diagnose A-T and carriers of A-T that uses nuclear staining of LCL's and PBMC's to measure ATM-dependent phosphorylation of structural maintenance of chromosomes 1 (SMC1) following DNA damage (FC-pSMC1 assay) (Nahas et al., 2009). While these flow assays offer a rapid and efficient testing method for diagnosing DNA repair defects, the colony survival assay (CSA) remains the current gold standard for detecting radiosensitivity until more sensitive assays can be defined. In addition, these assays can be used for prenatal diagnosis on amniocytes or chorionic villi cells.

\subsection{IDdiagnostics registry}

The IDdiagnostics registry was established to provide information for physicians and other health care professionals on diagnostic testing approaches for the detection of immunodeficiencies (Samarghitean et al., 2004). Available at http://bioinf.uta.fi/IDdiagnostics, the database contains information for 30 ID-related genetic disorders and a database of available clinical tests for diagnosis (Table 2). The clinical test database available in the registry contains information about clinical data, immune status, studies of function, antibody response, cell function, enzyme assays, clinical function, and apoptosis assays. The directory also lists the centers and laboratories performing clinical and genetic tests and allows labs to submit a form to the database to list their available tests in the registry. The purpose of the IDdiagnostics registry is to assist in the early diagnosis of immunodeficiencies.

\section{Hematological abnormalities}

\subsection{Hemophilia $A$ and $B$}

Hemophilia $\mathrm{A}$ and $\mathrm{B}$ are the most common genetic coagulation deficiencies. Hemophilia $A$ is the result of a defect in the coagulation Factor VIII gene while type B is caused by a mutation in the Factor IX gene. Both genes are cofactors for the factor IX gene and are required in the activation of factor $\mathrm{X}$ for coagulation. These defects disrupt the coagulation cascade with the formation of fibrin-deficient clots. Patients with hemophilia A and B present with severe bleeding. The prevalence of hemophilia $A$ is approximately 1:5000 male births while the prevalence of hemophilia $B$ is approximately 1:20,000 male births. While rare, hemophilia A and B can occur in females. Treatment for patients with severe hemophilia is intravenous recombinant or plasma concentrate Factor VIII.

\subsubsection{Flow cytometric assays for diagnosis}

Coagulation deficiencies can be detected with flow cytometry by measuring platelet activation. Markers for measuring platelet activation include the glycoprotein GPIIb-IIIa complex, the exposure of granule membrane proteins, the binding of secreted platelet proteins, and the development of a procoagulant surface (Michelson et al., 2000). An anticoagulant such as buffered sodium citrate can minimize formation of platelet aggregates and activationdependent monoclonal antibodies targeted against these markers can be used to assess protein aggregation (Michelson et al., 2000). There are several advantages to using flow 


\section{Table 2}

Primary immunodeficiencies in the IDdiagnostics genetic test Database. Source: Samarghitean C, Väliaho J, Vihinen M. Online registry of genetic and clinical immunodeficiency diagnostic laboratories, IDdiagnostics. J Clin Immunol. 2004 Jan. 24(1):53-61.

\begin{tabular}{|c|c|c|c|}
\hline Disease & $\begin{array}{l}\text { OMIM } \\
\text { No. }\end{array}$ & $\begin{array}{l}\text { Gene } \\
\text { symbol }\end{array}$ & $\begin{array}{l}\text { Number } \\
\text { of entries }\end{array}$ \\
\hline \multicolumn{4}{|c|}{ Deficiencies predominantly affecting antibody production } \\
\hline X-linked agammaglobulinemia (XLA) & 300300 & BTK 8 & 8 \\
\hline$\mu$-Heavy-chain gene deletions & 147020 & IGLL1 & 2 \\
\hline$\kappa$-Light-chain deficiency & 147200 & $I G K C$ & 1 \\
\hline \multicolumn{4}{|l|}{ Combined $B$ and $T$ cell immunodeficiencies } \\
\hline $\begin{array}{l}\text { X-linked lymphoproliferative syndrome } \\
\text { (XLP) }\end{array}$ & 308240 & SH2D1A & 6 \\
\hline $\begin{array}{l}\text { Purine nucleoside phosphorylase } \\
\text { deficiency }\end{array}$ & 164050 & $N P$ & 2 \\
\hline ZAP-70 deficiency & 176947 & ZAP70 & 2 \\
\hline $\mathrm{CD} 3 \gamma$ deficiency & 186740 & $C D 3 G$ & 1 \\
\hline RAG1 deficiency & 179615 & RAG1 & 6 \\
\hline RAG2 deficiency & 179616 & RAG2 & 6 \\
\hline Artemis deficiency & 605988 & DCLRE1C & 1 \\
\hline X-linked hyper IgM syndrome (XHIM) & 308230 & TNFSF5 & 4 \\
\hline Cytidine deaminase (AID) deficiency & 605257 & AICDA & 1 \\
\hline $\begin{array}{l}\text { X-linked severe combined } \\
\text { immunodeficiency (XSCID) }\end{array}$ & 300400 & IL2RG & 6 \\
\hline Jak3 deficiency & 600173 & JAK3 & 2 \\
\hline MHCII deficiency (defect in CIITA) & 60005 & MHC2TA & 1 \\
\hline MHCII deficiency (defect in RFX5) & 601863 & RFX5 & 1 \\
\hline CD4 deficiency & 153390 & $L C K$ & 1 \\
\hline CVID-ICOS deficiency & 240500 & ICOS & 1 \\
\hline IL7R deficiency & 146661 & IL7R & 1 \\
\hline $\begin{array}{l}\text { Familial hemophagocytic } \\
\text { lymphohistiocytosis }\end{array}$ & 603552 & PRF1 & 2 \\
\hline \multicolumn{4}{|c|}{ Other well-defined immunodeficiency syndromes } \\
\hline Wiskott-Aldrich syndrome (WAS) & 300392 & WASP & 7 \\
\hline $\begin{array}{l}\text { Autoimmune lymphoproliferative } \\
\text { syndrome (ALPS), defect in TNFRSF6 }\end{array}$ & 601859 & TNFRSF6 & 2 \\
\hline \multicolumn{4}{|l|}{ Defects of phagocyte function } \\
\hline $\begin{array}{l}\text { Autosomal recessive CGD p22phox } \\
\text { deficiency }\end{array}$ & 233690 & $C Y B A$ & 2 \\
\hline $\begin{array}{l}\text { Autosomal recessive CGD p47phox } \\
\text { deficiency }\end{array}$ & 233700 & NCF1 & 2 \\
\hline $\begin{array}{l}\text { Autosomal recessive CGD p67phox } \\
\text { deficiency }\end{array}$ & 233710 & NCF2 & 2 \\
\hline $\begin{array}{l}\text { X-linked chronic granulomatous } \\
\text { disease (XCGD) }\end{array}$ & 306400 & $C Y B B$ & 3 \\
\hline Leukocyte adhesion deficiency 1 (LAD1) & 600065 & ITGB2 & 3 \\
\hline Chediak-Higashi syndrome & 214500 & CHS1 & 1 \\
\hline Griscelli syndrome & 214450 & MYO5A & 1 \\
\hline \multicolumn{4}{|l|}{ Interferon $\gamma$-associated immunodeficiency } \\
\hline IFN- $\gamma$ receptor deficiency & 107470 & IFNGR1 & 1 \\
\hline Total & & & 79 \\
\hline
\end{tabular}

Immunodefing Diagnostics Information Resource (database online). Copyright IMT Bioinformatics, University of Tampere, 2000-2010. Available at http://bioinf.uta.fi/IDdiagnostics/.

cytometry for diagnosis of coagulation deficiencies such as hemophilia A and B. Platelets can be analyzed from whole blood with little manipulation of the sample, which means cells can remain viable for further testing. The activation and reactivity of circulating platelets including platelet surface membrane modifications can be detected (Michelson et al., 2000). In addition, a low volume of blood is needed, which would allow for prenatal testing on flow-sorted fetal cells.

\subsection{Glantzmann's thrombasthenia}

Glanzmann's thrombasthenia (GT) is an inherited autosomal recessive bleeding disorder caused by an abnormality of the platelet glycoprotein (GP) receptor. GT is characterized by absent or markedly reduced platelet GP IIb or IIIa and results in a lifelong bleeding tendency due to defective platelet plug formation (Nair et al., 2005). The bleeding tendency is variable but may be severe. Patients with type I GT have totally absent or $<5 \%$ of GPIIb-IIIa while patients with type II GT have reduced levels (Nair et al., 2005). Type III GT is characterized by normal levels of GPIIb-IIIa, but they are functionally inactive forms (Nair et al., 2005). The prothrombin time (PT), partial thromboplastin time (aPTT), and platelet counts are normal in patients with GT; only the bleeding time (BT) is prolonged. GT is a rare disorder, inherited in an autosomal recessive fashion, and affects about one in one million individuals. The diagnosis is usually made at a young age, and there is a history of epistaxis, gingival bleeding, and easy bruising. A higher frequency is noted in certain ethnic groups, e.g., Iraqi Jews, Arabs, Iranians, French gypsies, and Indians (Sazena and Kannan, 2009). Recombinant factor VIla and tranexamacid may be used to enhance platelet function in patients with GT. In severe cases, bone marrow transplantation may be considered.

\subsubsection{Flow cytometric assays for diagnosis}

Flow cytometric assays with antibodies against GPIIb and GPIIIa can be used to assess platelet surface expression of GPIIb-IIIa receptors for diagnosis of type I and II GT. GT can be diagnosed prenatally using fetal cell sorted blood. Using flow cytometry, platelets can be incubated and stained with fluorescein isothiocyanate conjugated monoclonal antibodies CD41 and CD61 to analyze for platelet GPIIb/IIIa receptors (Kannan et al., 2010). This method allowed for a normal control response to CD61 of $87.3 \%$ while in patients with GT, it was $0.0 \%$. Another flow assay has been described that uses antihuman fibrinogen antibody to detect platelets GPIIb, GPIIIa and GPIIb-IIIa using FITC-labeled antibodies to the corresponding antigens (Nair et al., 2005).

\subsection{Fanconi's anemia}

Fanconi anemia (FA) is a rare autosomal recessive disorder of proteins responsible for DNA repair. It is characterized by chromosomal hypersensitivity to cross linking agents such as mitomycin $\mathrm{C}$ and bone marrow failure (Tischkowitz and Hodgson, 2003). There are 13 genes associated with FA. Clinically, about $60-75 \%$ of FA patients have congenital defects and $20 \%$ or more of FA patients develop cancer, most often acute myelogenous leukemia, while $90 \%$ of FA patients develop bone marrow failure by age 40. Congenital defects associated with FA include hypoplasia of the thumbs and radial hypoplasia, short stature, hypogonadism, and hypo- or hyper- skin pigmentation. While total blood counts may be normal at birth, within the first 10 years of life patients will typically develop macrocytosis. In the second decade of life, over half of FA patients will develop pancytopenia (Tischkowitz and Hodgson, 2003). FA is associated with abnormal DNA repair, and as the bone marrow is an area of dynamic cell division, patients with FA have an 
increased risk of myelodysplastic syndromes, acute myeloid leukemia, and complete bone marrow failure. The incidence of Faconi anemia is 1:350,000 live births. Treatment with androgens and hematopoietic (blood cell) growth factors can help bone marrow failure temporarily, with $50-75 \%$ of patients responding, but the long-term treatment is bone marrow transplant or hematopoietic stem cell transplantation from a related donor. Two-year survival after transplantation is highest when it is done in the first decade of life.

\subsubsection{Flow cytometric assays for diagnosis}

Flow cytometric assays can identify cells that undergo chromosome breakage after treatment with DNA cross linking agents. FA patients have cell cycle disturbances in the G2 phase compartment of the cell cycle, which can be assayed by adding DNA cross linking agents such as mitomycin C (MMC) 35 or diepoxybutane (DEB)36 (Tischkowitz and Hodgson, 2003). For prenatal diagnosis of FA, Bechtold et al. (2006) analyzed the use of single parameter flow cytometry on amniotic fluid (AF) cell cultures and dual parameter flow cytometry on 72-hour umbilical cord (UC) blood cultures using mitomycin C (MMC) to identify G2-phase accumulations. Using single parameter flow cytometry on the AF cells, they identified 2 positive and 9 negative cases on the basis of MMC sensitivity and using dual parameter flow on the UC cells, they identified 8 negative and 2 positive cases. However, they found that dual flow cytometry applied to AF cells grown in the presence of bromodeoxyuridine (BrdU) yielded falsepositive and false-negative results. Based on their findings, they recommend that a flow cytometric assay should be used as a prenatal screening procedure in patients with a low risk of FA while patients with a high risk should receive chromosomal breakage testing for a definitive diagnosis.

\subsection{Bernard Soulier syndrome (BSS)}

Bernard Soulier syndrome (BSS) is a rare autosomal recessive disorder that causes qualitative and quantitative abnormalities of the Gp1b-IX-V complex required for platelet adhesion and clot formation (Bowers et al., 2006). The Bernard Soulier gene has been mapped to the short arm of chromosome 17. BSS usually presents in infancy, childhood or early adulthood with repeated episodes of bruising, epistaxis, and/or gingival bleeding. Spontaneous bleeding is unusual. Severe bleeding episodes may require platelet and blood transfusions, as well as recombinant activated factor VII, desmopressin acetate, or antifibrinolytic agents. For patients with moderate to severe forms of the disease, activities may need to be limited to avoid bleeding episodes. BSS is characterized by an absent response to ristocetin and delayed aggregation by thrombin (Bowers et al., 2006). It has a prevalence of $1: 1,000,000$, although this may be an underestimate due to misdiagnosis or under-reporting. The only curative treatment option is bone marrow transplantation.

\subsubsection{Flow cytometric assays for diagnosis}

Platelet aggregation can be measured by flow cytometry to assist in the diagnosis of BSS. In an assay performed by Bowers et al., plasma was separated from peripheral blood using potassium ethylenediamine tetraacetic acid and platelets were labeled with monoclonal antibodies to Gplb (antiCD42b-RPE), GpIIb (anti-CD41-FITC) and GpIIIa (anti-CD16-
FITC) (Bowers et al., 2006). This assay showed normal expression of GpIIb and GpIIIa, but a complete absence of GpIb. An absence of GpIb as detected by flow cytometry in conjunction with an absence of ristocetin response in a platelet aggregation study can offer a confirmatory diagnosis of BSS in patients who present with clinical symptoms. Prenatal diagnosis using amniotic fluid or chorionic villous sampling can be performed with this GP1BA flow assay.

\section{Summary}

Fetal sorted cells from maternal blood offer a non-invasive approach for prenatal diagnosis reducing the potential for fetal loss or injury associated with amniocentesis or chorionic villus sampling (CVS). This method has proved challenging however, as the estimated number of fetal cells circulating in maternal blood is 1 in $10^{4}$ to $10^{6}$ at any time during pregnancy and the lack of specific fetal-cell markers makes it difficult to accurately distinguish fetal from maternal cells. While MACS and FACS analysis can successfully identify fetal cells in maternal blood, the low number of cells poses an obstacle for diagnosis. Further studies are needed including a large scale clinical trial to assess whether cells obtained using this method in conjunction with FISH and genetic testing can be used for prenatal diagnosis.

However, flow cytometry can be used for a confirmatory diagnosis in several immunological disorders and as a tool to isolate cells that may then be used for highly sensitive molecular testing that can identify a gene defect for a definitive diagnosis and/or confirm carrier identification. Protein-based and functional flow assays offer a fast and objective method for a definitive diagnosis (DHR flow assay) or a confirmatory diagnosis in conjunction with other diagnostic tests. For coagulation deficiencies, flow cytometry can be used to assess platelet activation and reactivity on whole blood samples. In addition, because low volumes of blood are needed, a neonatal diagnosis is possible (Michelson et al., 2000). There are several limitations to using flow cytometry as a diagnostic tool. Flow cytometric assays often require expensive reagents that may not be routinely available in a clinical setting and some analyses require highly skilled personnel to perform (Notarangelo and Sorensen, 2008). The ongoing development of new easier to operate instrument platforms capable of measuring multiple parameters, plus the advances in reagents and dye conjugations will help this technology continue to transition from the research setting into a key diagnostic tool in clinical medicine.

\section{References}

Bakke, A.C., Purtzer, M.Z., Wildin, R.S., 2004. Prospective immunological profiling in a case of immune dysregulation, polyendocrinopathy, enteropathy, X-linked syndrome (IPEX). Clin. Exp. Immunol. 137, 373.

Bartolomé, J., Porta, F., Lafranchi, A., Rodríguez-Molina, J.J., Cela, E., Cantalejo, A., Fernández-Cruz, E., Gómez-Pineda, A., Ugazio, A.G., Notarangelo, L.D., Gil, J., 2002. B cell function after haploidentical in utero bone marrow transplantation in a patient with severe combined immunodeficiency. Bone Marrow Transplant. 29, 625.

Bechtold, A., Friedl, R., Kalb, R., Gottwald, B., Neveling, K., Gavvovidis, I., Herterich, S., Schindler, D., Hoehn, H., 2006. Prenatal exclusion/ confirmation of Fanconi anemia via flow cytometry: a pilot study. Fetal Diagn. Ther. 21, 118.

Berger, C., Uehlinger, J., Ghelfi, D., Blau, N., Fanconi, S., 1995. Comparison of Creactive protein and white blood cell count with differential in neonates at risk for septicaemia. Eur. J. Pediatr. 154, 138. 
Berner, R., Tuxen, B., Clad, A., Forster, J., Brandis, M., 2000. Elevated gene expression of interleukin-8 in cord blood is a sensitive marker for neonatal infection. Eur. J. Pediatr. 159, 205.

Bianchi, D.W., Flint, A.F., Pizzimenti, M.F., Knoll, J.H., Latt, S.A., 1990. Isolation of fetal DNA from nucleated erythrocytes in maternal blood. Proc. Natl Acad. Sci. USA 87, 3279.

Bianchi, D.W., Simpson, J.L., Jackson, L.G., Elias, S., Holzgreve, W., Evans, M.I., Dukes, K.A., Sullivan, L.M., Klinger, K.W., Bischoff, F.Z., Hahn, S., Johnson, K.L., Lewis, D., Wapner, R.J., de la Cruz, F., 2002. Fetal gender and aneuploidy detection using fetal cells in maternal blood: analysis of NIFTY I data. National Institute of Child Health and Development Fetal Cell Isolation Study. Prenat. Diagn. 22, 609.

Bischoff, F.Z., Lewis, D.E., Nguyen, D.D., Murrell, S., Schober, W., Scott, J., Simpson, J.L., Elias, S., 1998. Prenatal diagnosis with use of fetal cells isolated from maternal blood: five-color fluorescent in situ hybridization analysis on flow-sorted cells for chromosomes X, Y, 13, 18, and 21. Am. J. Obstet. Gynecol. 179, 203.

Bowers, M.J., Orr, N.J., Dempsey, S.I., Alexander, H.D., 2006. Molecular genetics and transfusion management in a child with Bernard Soulier syndrome. Blood Coagul. Fibrinolysis 17, 409.

Boyle, J.M., Buckley, R.H., 2007. Population prevalence of diagnosed primary immunodeficiency diseases in the United States. J. Clin. Immunol. 27, 497.

Buckley, R.H., Schiff, S.E., Schiff, R.I., Markert, L., Williams, L.W., Roberts, J.L., Myers, L.A., Ward, F.E., 1999. Hematopoietic stem-cell transplantation for the treatment of severe combined immunodeficiency. N. Engl. J. Med. $340,508$.

Conley, M.E., Notarangelo, L.D., Etzioni, A., 1999. Diagnostic criteria for primary immunodeficiencies. Representing PAGID (Pan-American Group for Immunodeficiency) and ESID (European Society for Immunodeficiencies). Clin. Immunol. 93, 190.

Franz, A.R., Steinbach, G., Kron, M., Pohlandt, F., 1999. Reduction of unnecessary antibiotic therapy in newborn infants using interleukin8 and C-reactive protein as markers of bacterial infections. Pediatrics $104,447$.

Freyer, D.R., Gowans, K.L., Warzynski, M., Lee, W.I., 2004. Flow cytometric diagnosis of X-linked hyper-IgM syndrome: application of an accurate and convenient procedure. J. Pediatr. Hematol./Oncol. 26, 363.

Gänshirt, D., Smeets, F.W., Dohr, A., Walde, C., Steen, I., Lapucci, C., Falcinelli, C., Sant, R., Velasco, M., Garritsen, H.S., Holzgreve, W., 1998. Enrichment of fetal nucleated red blood cells from the maternal circulation for prenatal diagnosis: experiences with triple density gradient and MACS based on more than 600 cases. Fetal Diagn. Ther. 13, 276.

Gatti, R.A., Boder, E., Good, R.A., 2007. Immunodeficiency, radiosensitivity, and the XCIND syndrome. Immunol. Res. 38, 87.

Gavin, M.A., Torgerson, T.R., Houston, E., DeRoos, P., Ho, W.Y., Stray-Pedersen, A., Ocheltree, E.L., Greenberg, P.D., Ochs, H.D., Rudensky, A.Y., 2006 Single-cell analysis of normal and FOXP3-mutant human T cells: FOXP3 expression without regulatory T cell development. Proc. Natl Acad. Sci. USA 103, 6659.

Gendrel, D., Assicot, M., Raymond, J., et al., 1996. Procalcitonin as a marker for the early diagnosis of neonatal infection. J. Pediatr. 128, 570.

Hahn, S., Holzgreve, W., 2002. Prenatal diagnosis using fetal cells and cellfree fetal DNA in maternal blood: what is currently feasible? Clin. Obstet Gynecol. 45, 649.

Hatherill, M., Tibby, S.M., Sykes, K., Turner, C., Murdoch, I.A., 1999. Diagnostic markers of infection: comparison of procalcitonin with $C$ reactive protein and leucocyte count. Arch. Dis. Child. 81, 417.

Herzenberg, L.A., Bianchi, D.W., Schröder, J., Cann, H.M., Iverson, G.M., 1979 Fetal cells in the blood of pregnant women: detection and enrichment by fluorescence-activated cell sorting. Proc. Natl Acad. Sci. USA 76, 1453.

Hoffmann, J.M.L., 2009. Neutrophil CD64: a diagnostic marker for infection and sepsis. Clin. Chem. Lab. Med. 47, 903.

Hudson, L.L., Louise-Markert, M., Devlin, B.H., Haynes, B.F., Sempowski, G.D., 2007. Human T cell reconstitution in DiGeorge syndrome and HIV-1 infection. Semin. Immunol. 19, 297.

Jurges, E.S., Henderson, D.C., 1996. Inflammatory and immunological markers in preterm infants: correlation with disease. Clin. Exp. Immunol. 105,551

Kanegane, H., Futatani, T., Wang, Y., Nomura, K., Shinozaki, K., Matsukura, H., Kubota, T., Tsukada, S., Miyawaki, T., 2001. Clinical and mutational characteristics of X-linked agammaglobulinemia and its carrier identified by flow cytometric assessment combined with genetic analysis. J. Allergy Clin. Immunol. 108, 1012.

Kannan, M., Yadav, B.K., Ahmad, F., Saxena, R., 2010. Role of RFLP using TspRI for carrier detection in Glanzmann's thrombasthenia: a report on two families. Int. J. Lab. Hematol. 32, e158.

Knutsen, A.P., Steffen, M., Wassmer, K., Wall, D.A., 2003. Umbilical cord blood transplantation in Wiskott Aldrich syndrome. J. Pediatr. 142, 519.

Kobrynski, L.J., 2006. Combined immune deficiencies in children. J. Infus. Nurs. 29, 206
Koker, M.Y., Sanal, O., de Boer, M., Tezcan, I., Metin, A., Tan, C., Ersoy, F., Roos, D., 2006. Skewing of X-chromosome inactivation in three generations of carriers with X-linked chronic granulomatous disease within one family. Eur. J. Clin. Investig. 36, 257.

Küster, H., Weiss, M., Willeitner, A.E., Detlefsen, S., Jeremias, I., Zbojan, J., Geiger, R., Lipowsky, G., Simbruner, G., 1998. Interleukin-1 receptor antagonist and interleukin- 6 for early diagnosis of neonatal sepsis 2 days before clinical manifestation. Lancet 352, 1271.

Le, B.S., Geha, R.S., 2006. IPEX and the role of Foxp3 in the development and function of human Tregs. J. Clin. Invest. 116, 1473.

Levy, J., Espanol-Boren, T., Thomas, C., Fischer, A., Tovo, P., Bordigoni, P., Resnick, I., Fasth, A., Baer, M., Gomez, L., Sanders, E.A., Tabone, M.D., Plantaz, D., Etzioni, A., Monafo, V., Abinun, M., Hammarstrom, L., Abrahamsen, T., Jones, A., Finn, A., Klemola, T., DeVries, E., Sanal, O., Peitsch, M.C., Notarangelo, L.D., 1997. Clinical spectrum of X-linked hyper-IgM syndrome. J. Pediatr. 131, 47.

Liuba, K., Pronk, C.J., Stott, S.R., Jacobsen, S.E., 2009. Polyclonal T-cell reconstitution of X-SCID recipients after in utero transplantation of lymphoid-primed multipotent progenitors. Blood 113, 4790.

Markert, M.L., Sarzotti, M., Ozaki, D.A., Sempowski, G.D., Rhein, M.E., Hale, L.P., Le Deist, F., Alexieff, M.J., Li, J., Hauser, E.R., Haynes, B.F., Rice, H.E., Skinner, M.A., Mahaffey, S.M., Jaggers, J., Stein, L.D., Mill, M.R., 2003. Thymus transplantation in complete DiGeorge syndrome: immunologic and safety evaluations in 12 patients. Blood 102, 1121.

Michelson, A.D., Barnard, M.R., Krueger, L.A., Frelinger, A.L., Furman, I.M., 2000. Evaluation of platelet function by flow cytometry. Methods 21, 259.

Nahas, S.A., Gatti, R.A., 2009. DNA double strand break repair defects, primary immunodeficiency disorders, and 'radiosensitivity'. Curr. Opin. Allergy Clin. Immunol. 9, 510.

Nahas, S.A., Butch, A.W., Du, L., Gatti, R.A., 2009. Rapid flow cytometry-based structural maintenance of chromosomes 1 (SMC1) phosphorylation assay for identification of ataxia-telangiectasia homozygotes and heterozygotes. Clin. Chem. 55, 463.

Nair, S., Ghosh, K., Shetty, S., Mohanty, D., 2005. Mutations in GPIIIa molecule as a cause for Glanzmann thrombasthenia in Indian patients. J Thromb Haemost. 3, 482.

Ng, P.C., Cheng, S.H., Chui, K.M., Fok, T.F., Wong, M.Y., Wong, W., et al., 1997. Diagnosis of late onset neonatal sepsis with cytokines, adhesion molecule, and C-reactive protein in preterm very low birthweight infants. Arch. Dis. Child. Fetal Neonatal Ed. 77, F221.

Ng, P.C., Li, K., Wong, R.P.O., Chui, K.M., Wong, E., Fok, T.F., 2002. Neutrophil CD64 Expression: A Sensitive Diagnostic Marker for Late-Onset Nosocomial Infection in Very Low Birthweight Infants. Pediatr. Res. 51, 296.

Notarangelo, L.D., 2010. Primary immunodeficiencies. J. Allergy Clin. Immunol. 125, S182.

Notarangelo, L.D., Sorensen, R., 2008. Is it necessary to identify molecular defects in primary immunodeficiency disease? J. Allergy Clin. Immunol. $122,1069$.

Ochs, H.D., Thrasher, A.J., 2006. The Wiskott-Aldrich syndrome. J. Allergy Clin. Immunol. 117, 725 Review.

Porcedda, P., Turinetto, V., Brusco, A., Cavalieri, S., Lantelme, E., Orlando, L., Ricardi, U., Amoroso, A., Gregori, D., Giachino, C., 2008. A rapid flow cytometry test based on histone H2AX phosphorylation for the sensitive and specific diagnosis of ataxia telangiectasia. Cytom. A 73, 508.

Price, J.O., Elias, S., Wachtel, S.S., Klinger, K., Dockter, M., Tharapel, A., Shulman, L.P., Phillips, O.P., Meyers, C.M., Shook, D., et al., 1991. Prenatal diagnosis with fetal cells isolated from maternal blood by multiparameter flow cytometry. Am. J. Obstet. Gynecol. 165, 1731.

Puck, J.M., SCID Newborn Screening Working Group, 2007. Population-based newborn screening for severe combined immunodeficiency: steps toward implementation. J. Allergy Clin. Immunol. 120, 760

Richardson, M.P., Ayliffe, M.J., Helbert, M., Davies, E.G., 1998. A simple flow cytometry assay using dihydrorhodamine for the measurement of the neutrophil respiratory burst in whole blood: comparison with the quantitative nitrobluetetrazolium test. J. Immunol. Methods 219, 187.

Rodwell, R.L., Leslie, A.L., Tudehope, D.I., 1988. Early diagnosis of neonatal sepsis using a hematologic scoring system. J. Pediatr. 112, 761.

Routes, J.M., Grossman, W.J., Verbsky, J., Laessig, R.H., Hoffman, G.L., Brokopp, C.D., Baker, M.W., 2009. Statewide newborn screening for severe T-cell lymphopenia. JAMA 302, 2465.

Samarghitean, C., Valiaho, J., Vihinen, M., 2004. Online registry of genetic and clinical immunodeficiency diagnostic laboratories, IDdiagnostics. J. Clin. Immunol. 24, 53.

Sazena, R., Kannan, M., 2009. Glanzmann's thrombasthenia: an overview. Clin. Appl. Thromb. Hemost. 15, 152.

Sullivan, K.E., Mullen, C.A., Blaese, R.M., Winkelstein, J.A., 1994. A multiinstitutional survey of the Wiskott-Aldrich syndrome. J. Pediatr. 125, 876.

Tischkowitz, M.D., Hodgson, S.V., 2003. Fanconi anaemia. J. Med. Genet. 40, 1.

Trifari, S., Scaramuzza, S., Catucci, M., Ponzoni, M., Mollica, L., Chiesa, R., Cattaneo, F., Lafouresse, F., Calvez, R., Vermi, W., Medicina, D., Castiello, 
M.C., Marangoni, F. Bosticardo, M., Doglioni, C., Caniglia, M., Aiuti, A., Villa, A., Roncarolo, M.G., Dupré, L., 2010. Revertant T lymphocytes in a patient with Wiskott-Aldrich syndrome: analysis of function and distribution in lymphoid organs. J. Allergy Clin. Immunol. 125, 439.

van der Poll, T., de Waal Malefyt, R., Coyle, S.M., Lowry, S.F., 1997. Antiinflammatory cytokine responses during clinical sepsis and experimental endotoxemia: sequential measurements of plasma soluble interleukin-1 receptor type II, IL-10 and IL-13. J. Infect. Dis. 175, 118 .

Wagle, S., Grauaug, A., Kohan, R., Evans, S., 1994. C-reactive protein as a diagnostic tool of sepsis in very immature babies. J. Paediatr. Child Health $30,40$.

Wang, J.Y., Zhen, D.K., Falco, V.M., Farina, A., Zheng, Y.L., Delli-Bovi, L.C., Bianchi, D.W., 2000. Fetal nucleated erythrocyte recovery: fluorescence activated cell sorting-based positive selection using anti-gamma globin versus magnetic activated cell sorting using anti-CD45 depletion and anti-gamma globin positive selection. Cytometry 39, 224.

Westgren, M., Ringden, O., Bartmann, P., Bui, T.H., Lindton, B., Mattsson, J., Uzunel, M., Zetterquist, H., Hansmann, M., 2002. Prenatal T-cell reconstitution after in utero transplantation with fetal liver cells in a patient with X-linked severe combined immunodeficiency. Am. J. Obstet. Gynecol. 187, 475.

Ziegler, S.F., 2006. FOXP3: of mice and men. Annu. Rev. Immunol. 24, 209.

Zilow, G., Zilow, E.P., Burger, R., Linderkamp, O., 1993. Complement activation in newborn infants with early onset infection. Pediatr. Res. 34, 199. 